\title{
An ancient global disease: Scabies a systematic cross-section.
}

\section{Chiranjeeb Dey*}

Department of Zoology, Parasitology \& Immunobiology Unit, Serampore College, University of Calcutta, William Carey Road, Serampore 712 201, Hooghly, West Bengal, India

\begin{abstract}
Scabies is an age old parasitic disease of humans. The distribution is subject to a cycle of infection. Scabies generally affects poor hygienic families, basically residing in congested areas. The disease poses great impact on kids and young children. Very old persons also suffer from this disease. Aggravations cause serious concern when secondarily infected with bacteria like group A Streptococci and Staphylococcus aureus. The disease burden gets compounded by nephritis, rheumatic fever and sepsis in developing countries. The purpose of this article is to provide a systematic cross-section of scabies with regard to its complications and generate awareness to people in resource-poor countries.
\end{abstract}

Keywords: Mite, Neglected tropical diseases, Sarcoptes scabiei, Secondry infection, Scabies

Accepted on 24 August, 2018

Scabies is one of the commonest types of skin diseases recorded in developing countries. It is an ancient global disease and happens to be one of the first disease in humans with known cause. World Health Organization (WHO) considered it as a neglected skin disease with respect to public health in 2009 and was added to the Neglected Tropical Diseases portfolio in 2017. Scabies is a parasitosis caused by the itch and mange mite of family Sarcoptidae, Sarcoptes scabiei. This mite has cosmopolitan distribution. It is a small, oval, dorsally convex, ventrally flattened, eyeless mite, male measures $200-250 \mu \mathrm{m}$, and female 330-450 $\mu \mathrm{m}$. The first pair of legs terminated with suckers and claws whereas last pair of legs ends with long bristles (Figure 1). The life cycle is completed in 14-21 days. Hallmark feature includes intense itching and papular rash. The estimated world-wide annual prevalence of scabies is 300 million [1]. Further understanding of the disease burden is now required. In the succeeding paragraphs attempts have been made to systematic cross-sectioning of this nuisance contagious disease.

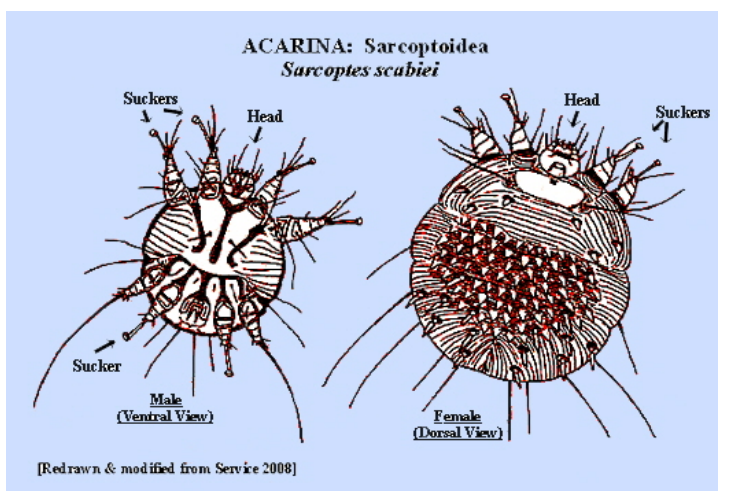

Figure 1. Morphology of Scabies mite, S. scabiei (Male and female)

\section{Epidemiology}

Scabies is endemic in tropical regions, with an average prevalence of $5-10 \%$ in children. Children of less than 6 years are highly prevalent and more so in less than 2 years of age.
With age the prevalence is decreasing Nair et al., and Suroshe et al. [2,3]. Very age old peoples are also victim of this disease. Scabies affects both sexes equally. According to WHO studies between 1971 and 2001 and reported cases, a scabies prevalence ranging between $0.2 \%$ and $24 \%$. Notably high prevalence has been reported from India, the South Pacific, and northern Australia Hay et al. [4]. In a rural Indian village, the prevalence of scabies was $70 \%$. This prevalence Figure 1 lies in between 20 and 50\% in other different parts of the world viz. Australia, Fiji, Vanuatu, Solomon Islands etc. Age, gender, ethnicity, overcrowding, hygiene, and season are considered as influencing factors for establishing the disease, Scabies (Table $1)$.

Table 1. Distribution of the scabies cases by various sociodemographic variables (After, Suroshe et al., [3])

\begin{tabular}{|l|l|}
\hline (n=264) & No. (\%) \\
\hline Age in years & \\
\hline$<2$ & $60(22.7)$ \\
\hline 2 to 5 & $87(33.0)$ \\
\hline 6 to 12 & $117(44.3)$ \\
\hline Gender & \\
\hline Female & \\
\hline Male & $114(43.2)$ \\
\hline Literacy level of parents & $150(56.8)$ \\
\hline Primary & $1(0.4)$ \\
\hline Up to 10 std & $87(33.0)$ \\
\hline$>10$ Std & $176(66.7)$ \\
\hline Economic status (Rupees) Per capita & \\
\hline Income of parent per month & $164(62.1)$ \\
\hline$<600$ & $92(34.8)$ \\
\hline 600 to 1200 & \\
\hline
\end{tabular}

J Parasit Dis Diagn Ther. 2018 Volume 3 Issue 1 
Citation: Dey C. An ancient global disease: Scabies a systematic cross-section. J Parasit Dis Diagn Ther. 2018;3(2):1-3. DOI: $10.4066 / 2591-7846.1000027$

\begin{tabular}{|l|l|}
\hline$>1200$ & $8(3.0)$ \\
\hline Total no. of family members & \\
\hline 3 & $7(2.7)$ \\
\hline 4 & $67(25.4)$ \\
\hline 5 & $109(41.3)$ \\
\hline 6 & $54(20.5)$ \\
\hline 7 & $20(7.6)$ \\
\hline 8 & $3(1.1)$ \\
\hline 9 & $1(0.4)$ \\
\hline 10 & $3(1.1)$ \\
\hline No. of rooms & \\
\hline 1 & $231(87.5)$ \\
\hline 2 & $33(12.5)$ \\
\hline Over Crowding & \\
\hline Absent & $26(9.8)$ \\
\hline Present & $238(90.2)$ \\
\hline & \\
\hline
\end{tabular}

\section{Characteriziation and Distribution of the Lesion}

Vesicular, papular, excoriation, eczematous eruptions, and impetigo with the risk of subsequent nephritis and secondary types of rashes and sometimes burrows are noted in the skin. Intense puritis have been observed at night. Increased mite activity with warmer skin temperatures may be an explanation in support of itching and scratching in undergarment areas Pramanik et al. [5]. Distribution is noted in the inter-digital space; Upper Limb, Lower Limb; palms/ soles; Face/ Scalp; and Genitals. The back is relatively free of involvement; the head is spared except in very young children. Scabies occurs in at least $2-4 \%$ of patients with HIV infection [6].

\section{Diagnosis}

In infants and young children, $75 \%$ of the mites can be found on the hands and feet. So, these are the best site to examine [7]. Common scabies in adults causes intense pruritis and skin lesions. It's one of the most difficult or one of the easiest diseases to diagnose. Inadequate experience and instruction pose hard for proper diagnosis. Visualizing burrows or the mite on dermoscopy can assist in the diagnosis Children usually scratch the rash areas repeatedly, the scratchy markings and crusting of the rash sometimes make this infection difficult to identify Suroshe et al. [3]. A serologic test specific for S. scabiei has been developed, with $100 \%$ sensitivity and $93.75 \%$ specificity, and may lead to more accurate diagnosis if widely used Jayaraj et al. [8]. There are no uniformly accepted test methods or examination procedures for diagnosis, which limits the interpretation of research and epidemiological findings. In this respect, a consensus (Delphi) study has been done involving international experts for the diagnosis of scabies Engelman et al. [9].

\section{Transmission}

Scabies is spread by close personal contact between host and frequently seen within the families through contaminated clothes and bed linen, sexual partners, amongst school-age children, and institutional people.

\section{Disease Management}

Benzyl benzoate $10 \%$ and $25 \%$ lotions, Pyrethrins: permethrin 5\% cream, Lindane: $1 \%$ lotion or cream Malathion: $0-5 \%$ lotions, Sulfiram: $25 \%$ solution, Sulphur: $2-10 \%$ are considered as principal topical scabicides [5]. Permethrin 5\% cream is safe and effective even in infants less than 1 month of age and appears to be the treatment of choice [10]. In large scale management (epidemic cases), Ivermectin is used as drug of choice.

The Canadian Paediatric Society and the Centers for Disease Control and Prevention recommend Permethrin cream 5\% as first-line therapy for patients older than 2 months of age. Sulphur $7 \%$ is a safe alternative for young infants. Lindane cream or lotion should be used with caution in children younger than 2 years of age.

Single administrations of permethrin 5\% and systemic Ivermectin are comparably effective Dressler et al. [11]. Hypersensitivity reactions after scabies treatment with oral ivermectin has been reported in some cases and that are due to the mass release of antigens caused by destruction of the mites. This is the reason for transient itching following treatment Usha and Gopalakrishnan et al. [12].

\section{Comment}

Global burden of disease, GBD study provides a way to measure and compare health loss from disease and injury across age, sex, location, and time. Mean percent change of Disability-adjusted life-years (DALYs) rate was less than $8 \%$ in all world regions except North-America Karimkhani et al. [13]. This parasitic disease presumed to be associated with the environmental dynamics of the respective countries/ provinces. Improved strategies are urgently needed to achieve control of scabies and its complications in endemic communities. Despite all efforts towards diagnosis and therapy, preventive measure is still lying a challenge to us. Therefore, improvements in the information networks involved in this disease is must to take the challenge.

\section{References}

1. Chosidow O. Clinical practices: Scabies. N Engl J Med. 2006;354(16):1718-27.

2. Nair BKH, Joseph A, Narayanan PI. Epidemiology of scabies. Indian J Dermatol Venereol. 1973;39(3):101-5.

3. Suroshe BB, Rathod KG, Kulkarni V S, et al. Scabies in children and its outcome with topical permethrin and oral ivermectin: a single center prospective study. Int J Contemp Pediatr. 2017;4(6):2083-7. 
4. Hay RJ, Steer AC, Engelman D, et al. Scabies in the developing world-its prevalence, complications, and management. Clin Microbiol Infect. 2012;18(4): 313-323.

5. Pramanik AK, Hansen RC. Transcutaneous Gamma benzene hexachloride absorption and toxicity in infants and children. Arch Demerol. 1979;115(10):1224-5.

6. Thappa DM. Common skin problems. Indian J Pediatr. 2002;69(8):701-6.

7. Heilesen B. Studies on Acarus scabiei and scabies. Acta Derm Venereologica. 1946;14:1-370.

8. Jayaraj R, Hales B, Viberg L, et al. A diagnostic test for scabies: IgE specificity for a recombinant allergen of Sarcoptes scabiei. Diagn Microbiol Infect Dis 2011;71(4): 403-7.

9. Engelman D, Fuller LC, Steer AC. Consensus criteria for the diagnosis of scabies: A Delphi study of international experts. PLoS Negl Trop Dis. 2018;12(5):e0006549.

10. Jaramillo F, Ayerbe. Ivermectin for Crusted Norwegian Scabies. Arch Dermatol. 1998;134:143-5.

11. Dressler C, Rosumeck S, Sunderkötter C, et al. The Treatment of Scabies. Dtsch Arztebl Int. 2016;113(45): 757-62.
12. Usha V, Gopalakrishnan Nair TV. A comparative study of oral ivermectin and topical permethrin cream in the treatment of scabies. J Am Acad Der- matol 2000;42:236-40.

13. Karimkhani C, ColombaraDV, Drucker AM, et al. The global burden of scabies: a cross-sectional analysis from the Global Burden of Disease Study 2015. Lancet Infect Dis. $2017 ; 17(12): 1247-54$.

\section{*Correspondence to:}

Chiranjeeb Dey

Department of Zoology

Parasitology \& Immunobiology Unit,

Serampore College, University of Calcutta

William Carey Road, Serampore 712 201, Hooghly,

West Bengal, India

E-mail: chiranjeeb123@yahoo.co.in 